\title{
Clinical significance of serum CA125 in diffuse malignant mesothelioma
}

Xu Cheng ${ }^{1,2}$, Hong-feng Gou', Ji-yan Liu', De-yun Luo ${ }^{1}$ and Meng Qiư*

\begin{abstract}
Background: Malignant mesothelioma (MM) is a rare and fatal neoplasm. For diffuse malignant mesothelioma (DMM) patients that were not suitable for cytoreductive surgery and hyperthermic intraperitoneal chemotherapy, systemic chemotherapy is the main treatment. There are no convenient tumor markers to predict the efficacy of treatment and disease progression. This study aimed to evaluate serum CA125 level as a biochemical marker of response to therapy and prognosis in patients with DMM.
\end{abstract}

Methods: A retrospective study was performed in a single medical institution from April 2008 to April 2014. Overall survival (OS) and prognostic factors were assessed.

Results: Forty-one patients were included with a median age of 53 years. The median OS of all patients was 10 months. Patients with baseline CA125 > $280 \mathrm{U} / \mathrm{ml}$ had worse OS compared with the patients that baseline CA125 $\leq 280 \mathrm{U} / \mathrm{ml}$. Baseline level of CA125, stage of disease, primary tumor location and systemic chemotherapy were independent prognostic factors associated with OS. In patients who received systemic chemotherapy, the decline in serum CA125 was associated with favorable OS and objective response according to modified Response Evaluation Criteria in Solid Tumors criteria.

Conclusions: The baseline level of serum CA125, accompanied with stage of disease, primary tumor location and systemic chemotherapy, could be regarded as independent prognostic factors for DMM patients. Otherwise, the change in serum CA125 can predict OS and response to systemic chemotherapy.

Keywords: CA-125 antigen, Drug therapy, Mesothelioma, Prognosis

\section{Background}

Malignant mesothelioma (MM) is a rare and fatal mesenchymal neoplasm arising from the serosal cavities (Kebapci et al. 2003), commonly in pleura and peritoneum, with a natural median survival of 6 months (Ruffie 1991; de Pangher Manzini et al. 1993). Treatment strategy for MM including palliative cytoreductive surgery (CRS), systemic chemotherapy and intrapeural or intraperitoneal chemotherapy does not obtain satisfactory results (Nonaka et al. 2005; Hadi et al. 2006; Herndon et al. 1998; Vogelzang et al. 2003; Mineo and Ambrogi 2012), with the median survival of less than 12 months

\footnotetext{
*Correspondence: qiumeng33@hotmail.com

1 Department of Medical Oncology, Cancer Center, West China Hospital, Sichuan University, No. 37, Guoxue Xiang Street, Chengdu 610041,

Sichuan Province, China

Full list of author information is available at the end of the article
}

(Creaney et al. 2013; Robinson and Lake 2005; Robinson et al. 2003; Zucali et al. 2011). Published paper demonstrated that cytoreductive surgery and hyperthermic intraperitoneal chemotherapy (CRS/HIPEC) is a potentially curative treatment for malignant peritoneal mesothelioma (MPeM) (Alexander et al. 2013).But because of the difficulty in early diagnosing, most patients are initially diagnosed in advanced stage that is not candidate for curative surgery (Grigoriu et al. 2007; Kao et al. 2011).

The serological biomarkers for response assessment and prognosis of diffuse malignant mesothelioma (DMM) are very useful and important for therapeutic decision-making. However, there is still no accepted tumor marker in routine clinical practice. Previous studies demonstrated that soluble mesothelin, with a sensitivity of $50 \%$ and a specificity of $95 \%$ (Robinson et al. 2003; Creaney et al. 2007), could be a relevant tumor marker

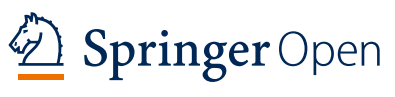

(c) 2016 Cheng et al. This article is distributed under the terms of the Creative Commons Attribution 4.0 International License (http://creativecommons.org/licenses/by/4.0/), which permits unrestricted use, distribution, and reproduction in any medium, provided you give appropriate credit to the original author(s) and the source, provide a link to the Creative Commons license, and indicate if changes were made. 
and the baseline serum level of mesothelin is an independent predictor of overall survival (Hollevoet et al. 2011; Linch et al. 2014). But few Chinese medical institutions had carried out mesothelin concentration. In clinical practice, we found that patients with DMM usually have elevated level of serum CA125. Furthermore, the elevated level of serum CA125 would decline when patients received systemic chemotherapy. Recent studies demonstrated mesothelin-CA125 binding is high affinity and co-expressed in mesothelioma (Rump et al. 2004; Gubbels et al. 2006; Kaneko et al. 2009). These evidence suggested elevated levels of serum CA125 might be sensitive for predicting disease progression (Kebapci et al. 2003; Hedman et al. 2003; Baratti et al. 2009), implying serum CA125 could be a potential prognostic marker. Similarly, there is no certain tumor marker for efficacy of systemic chemotherapy in DMM patients.

CA125 is a high molecular weight transmembrane glycoprotein well known as an independent predictor of progression-free survival (PFS) and overall survival (OS) in epithelial ovarian cancer (Chen et al. 2013). Furthermore, CA125 test is a regular and convenient tumor marker in clinical practice in China.

This retrospective study aimed to evaluate the prognostic and predictive value of the baseline levels of serum CA125 and change in serum CA125 during treatment in patients with DMM.

\section{Methods}

\section{Patients}

We identified patients attending Cancer Center of West China Hospital from April 2008 to April 2014 with a histologically or cytologically confirmed diagnosis of MM. All included patients were at stage III or IV that were unsuitable to curative surgery (Edge et al. 2010; Troshichev et al. 1988). The eligibility criteria included that age $\geq 18$ years; Eastern Cooperative Oncology Group (ECOG) performance status was $\leq 2$; histologically or cytologically confirmed diagnosis of MM and immunohistochemical tests excluded the possibilities of others metastatic carcinomas; must test at least the baseline level of serum CA125 before treatment and had followup data in detail. Patients with history of other concomitant neoplasm and chronic organ disorders that may affect the levels of serum CA125 were excluded. This study was approved by the Medical Ethical Committee of West China Hospital of Sichuan University (Chengdu, China) and written informed consent for data collection has been obtained.

In subgroup analysis to evaluate the change in serum CA125 as the indicator for the efficacy of systemic chemotherapy, we selected candidates from overall patients by following inclusive criteria: received at least one cycle of systemic chemotherapy; monitored the levels of serum CA125 at least every one or two cycles of chemotherapy and had corresponding efficacy evaluated by CT or MRI according to Response Evaluation Criteria in Solid Tumors (modified RECIST) criteria.

\section{CA125 assay}

CA125 (U/ml) levels were measured in serum using the CanAg CA125 assay (Roche Diagnostics). Assays were run according to manufacturer's instructions. The upper limit of normal range was $35 \mathrm{U} / \mathrm{ml}$.

\section{Treatment plan}

All treatment strategies were selected by treating physician based on the patients' physical and disease condition. The most common regimen of systemic chemotherapy was pemetrexed $500 \mathrm{mg} / \mathrm{m}^{2}$ and cisplatin $75 \mathrm{mg} / \mathrm{m}^{2}$ administered intravenously once every 21 days. Local chemotherapy was mostly administered as cisplatin $30-40 \mathrm{mg} / \mathrm{m}^{2}$ once every 21 days.

\section{Data collection}

Data on age, gender, primary tumor location, histological subtype, stage of disease, ECOG performance status, surgery, systemic chemotherapy, local chemotherapy, levels of serum CA125, efficacy assessment and survival information were collected.

Normal range of serum CA125 in our hospital was 0-35 U/ml. In chemotherapy subgroup, change in serum CA125 was defined as level of serum CA125 after treatment minus the baseline level of serum CA125. Modified RECIST (Byrne and Nowak 2004) was used to evaluate the efficacy of systemic chemotherapy. OS was calculated from the date of advanced disease diagnosis until the death or the last recorded date of follow-up.

\section{Statistical analysis}

Kaplan-Meier methods were used to conduct the best stratified level of baseline serum CA125 associated with OS and the univariate analysis of potential prognostic factors. In multivariate analysis, Cox's proportional hazards regression model was used to find the independent prognostic predictors for patients with DMM. Wilcoxon signed-rank test and Spearman rank correlation were used to conduct the association between the changes in serum CA125 and modified RECIST assessment. A value of $P<0.05$ were considered as statistically significant difference. The SPSS statistical software (IBM, V19) was used for all analyses.

\section{Results}

\section{Patient characteristics}

A total of 41 patients with DMM were included with a median age of 53 years (range from 24 to 80 ) and male 
preponderance (ratio: 2.15 to 1 ). The patient characteristics were shown in Table 1. Fourteen patients (34.2 \%) had pathological epithelioid tumors subtype and most patients (31 patients, $75.6 \%$ ) were at stage IV. More than half of patients (23 patients, $56.1 \%$ ) had received systemic chemotherapy, whereas only $26.8 \%$ of patients had undergone palliative CRS. The mean baseline serum CA125 was $351.3 / \mathrm{ml}$ (range $8.76-2017 \mathrm{U} / \mathrm{ml}$ ), with the values of 31 patients $(75.6 \%)$ were $>35 \mathrm{U} / \mathrm{ml}$.

Twenty-three diffuse malignant pleural mesothelioma (DMPIM) patients and 18 diffuse malignant peritoneal mesothelioma (DMPeM) patients were included in study. In DMPeM subgroup, 8 patients underwent palliative CRS while only 3 patients received palliative

\section{Table 1 Patient Characteristics}

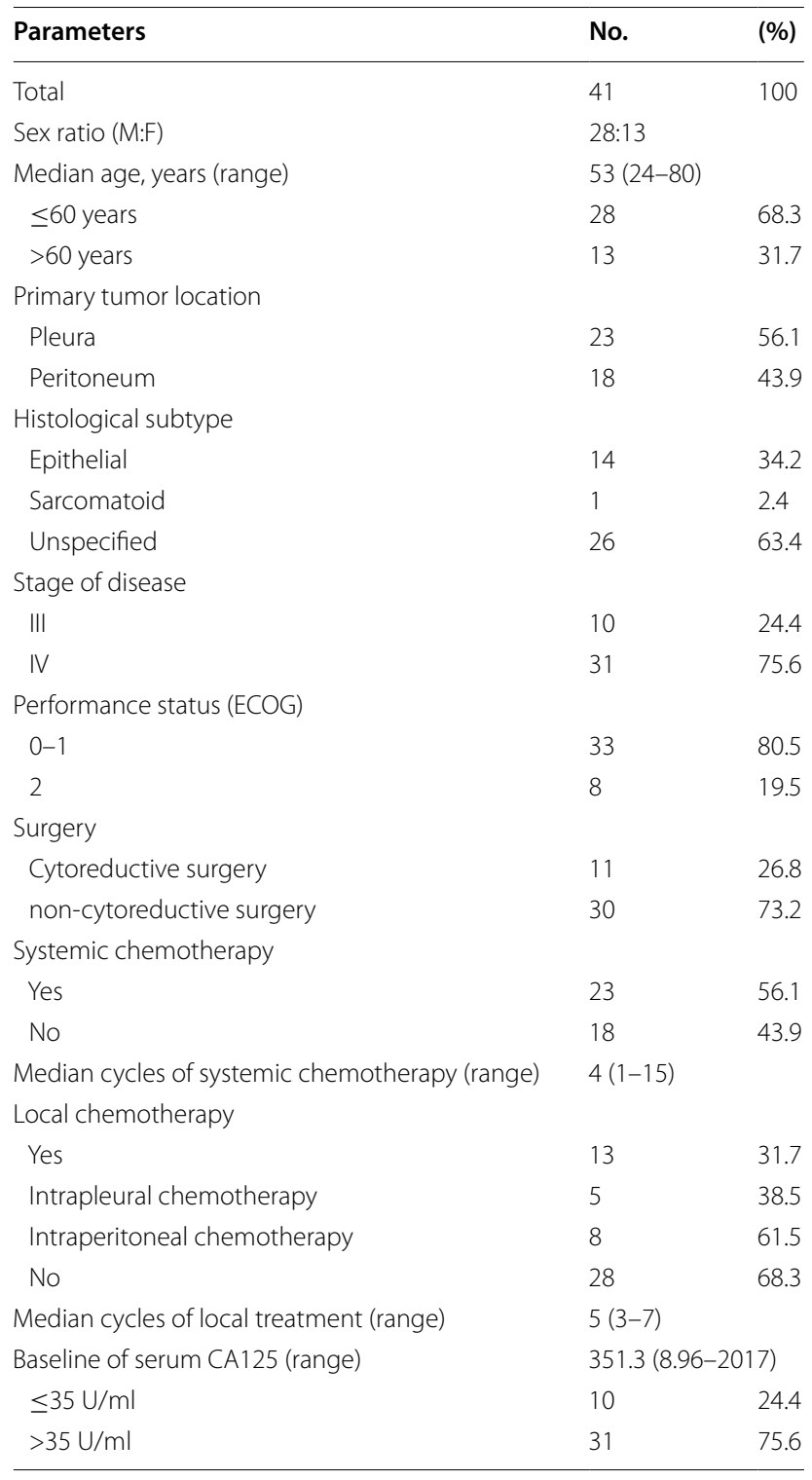

cytoreduction in DMPIM subgroup. There were thirty DMM patients without any palliative surgery in our study.

\section{Overall survival}

Median OS for all 41 patients was 10 months (range 1-48 months, $95 \%$ CI 4.633-15.367, Fig. 1). OS rates at 6,12 and 18 months was $62.4 \%, 44.6 \%$, and $41.4 \%$, respectively. Eighteen patients were alive when the study finished with a median follow-up of 30 months (range 2-61 months). Survival results for DMPIM patients and DMPeM patients were presented in Fig. 2.

\section{Factors associated with OS in univariate analysis}

A Log-rank test was used to find out potential prognostic factors associated with OS. The best stratified level of baseline serum CA125 (shown in Table 2) associated with OS was $280 \mathrm{U} / \mathrm{ml}$ in our study (eight times of upper normal limit, $P=0.045$, Fig. 3). Ten factors were considered into univariate analysis including age, gender, ECOG performance status, primary tumor location, pathological subtype, stage of disease, CRS, systemic chemotherapy, local chemotherapy and baseline level of serum CA125. The following factors correlated with a better outcome (shown in Table 3) included: 0-1 PS score (HR 3.013, $95 \%$ CI 1.208-7.513, $P=0.018$ ), tumor located in peritoneum (HR 0.236, $95 \%$ CI 0.091-0.613, $P=0.003$ ), epithelial subtype (HR 2.281, $95 \%$ CI 1.261 $4.124, P=0.006$ ), disease at stage III (HR 11.495, $95 \%$ CI $1.572-87.701, P=0.017)$, systemic chemotherapy (HR 0.340, $95 \%$ CI $0.142-0.810, P=0.015$ ) and the baseline level of serum CA125 $\leq 280 \mathrm{U} / \mathrm{ml}$ (HR 2.214, $95 \%$ CI 1.080-5.091, $P=0.045)$. Age, gender, CRS and local chemotherapy were not significantly related with OS.

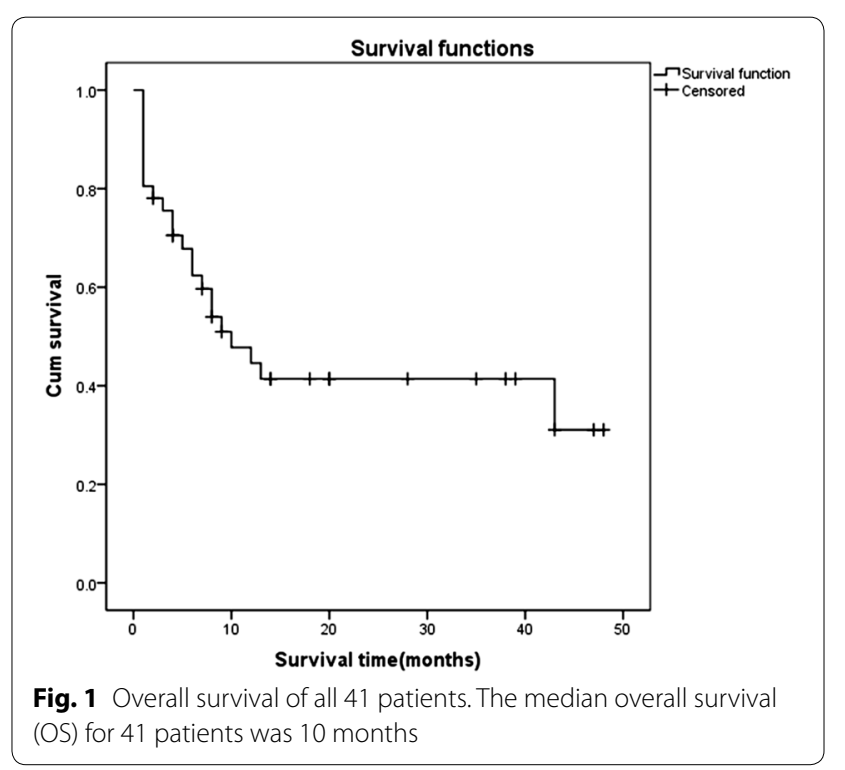




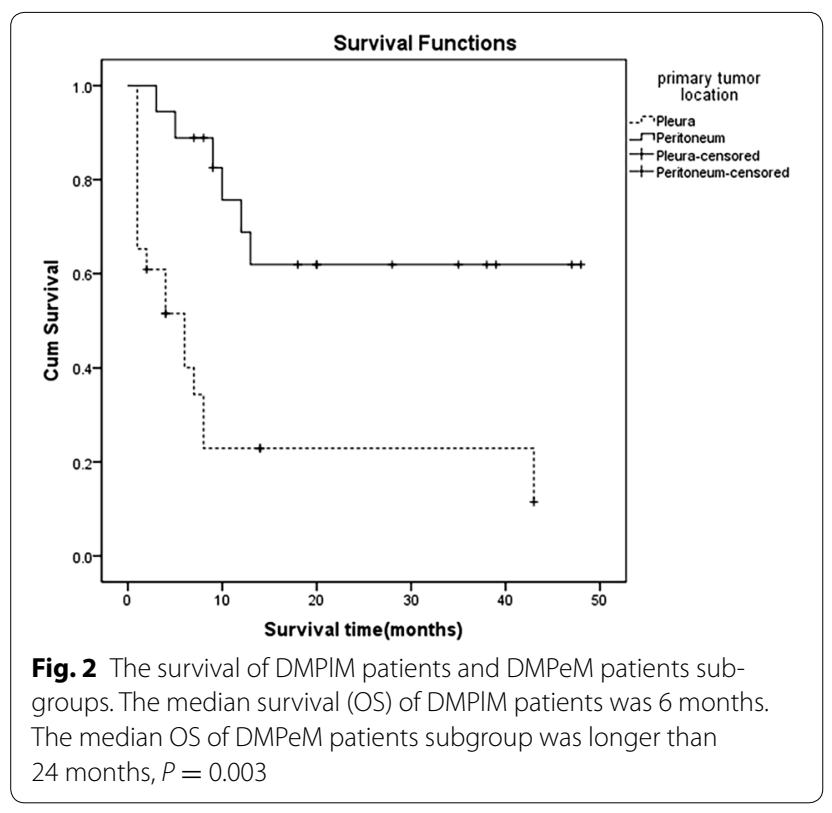

\section{Factors associated with OS in multivariate analysis}

Six factors were included into multivariate analysis conducted by a Cox proportional hazard model to identify the independent prognostic factors of OS. Four variables seemed to be the independent prognostic factors (shown in Table 4). Tumor located in peritoneum (HR 0.289, $95 \%$ CI 0.096-0.870, $P=0.027)$, disease at stage III (HR $14.571,95 \%$ CI 1.825-116.326, $P=0.011$ ), received systemic chemotherapy (HR 0.298, $95 \%$ CI 0.099-0.900, $P=0.032)$ and baseline level of serum CA125 $\leq 280 \mathrm{U} /$ $\mathrm{ml}$ (HR 3.412, $95 \%$ CI 1.265-9.208, $P=0.015$ ) were positive independent prognostic factors in patients with DMM.

\section{The correlation between CA125 change and OS or radiological objective response}

According the rigorous including criteria, 12 patients had regularly surveilled serum CA125 during systemic chemotherapy and finished corresponding efficacy evaluation. Wilcoxon signed-rank test assessed the differences in serum CA125 levels across the corresponding evaluation time points and found it differed significantly. Spearman rank correlation demonstrated a significant association between the change in serum CA125 and the response to systemic chemotherapy according to modified RECIST criteria $(\mathrm{rCA} 125=0.857, P<0.001$, shown in Table 5$)$.

The median OS for patients who received systemic chemotherapy was significant longer than OS of patients without systemic chemotherapy (median survival: 43 months in chemotherapy group vs. 4 months in chemotherapy-naïve group, $P=0.015)$. Similarly, the mean level of baseline serum CA125 in systemic chemotherapy
Table 2 Different stratified levels of baseline serum CA125 associated with overall survival in 41 patients

\begin{tabular}{lll}
\hline Baseline of serum CA125 (U/ml) & $\mathbf{X}^{\mathbf{2}}$ & $\boldsymbol{P}$ \\
\hline$\leq 35$ versus $>35$ & 2.501 & 0.114 \\
$\leq 42.61$ versus $>42.61^{\text {a }}$ & 2.924 & 0.087 \\
$\leq 70$ versus $>70$ & 1.715 & 0.190 \\
$\leq 138.60$ versus $>138.60^{\mathrm{a}}$ & 2.339 & 0.126 \\
$\leq 140$ versus $>140$ & 2.339 & 0.126 \\
$\leq 210$ versus $>210$ & 1.461 & 0.227 \\
$\leq 280$ versus $>280$ & 4.001 & 0.045 \\
$\leq 350$ versus $>350$ & 2.227 & 0.136 \\
$\leq 489.90$ versus $>489.90^{\mathrm{a}}$ & 1.352 & 0.245 \\
\hline
\end{tabular}

Normal range of serum CA125 in our hospital was $0-35 \mathrm{U} / \mathrm{ml}$

a The quartile of baseline serum CA125 in study was $42.61,138.60,489.90 \mathrm{U} / \mathrm{ml}$, respectively

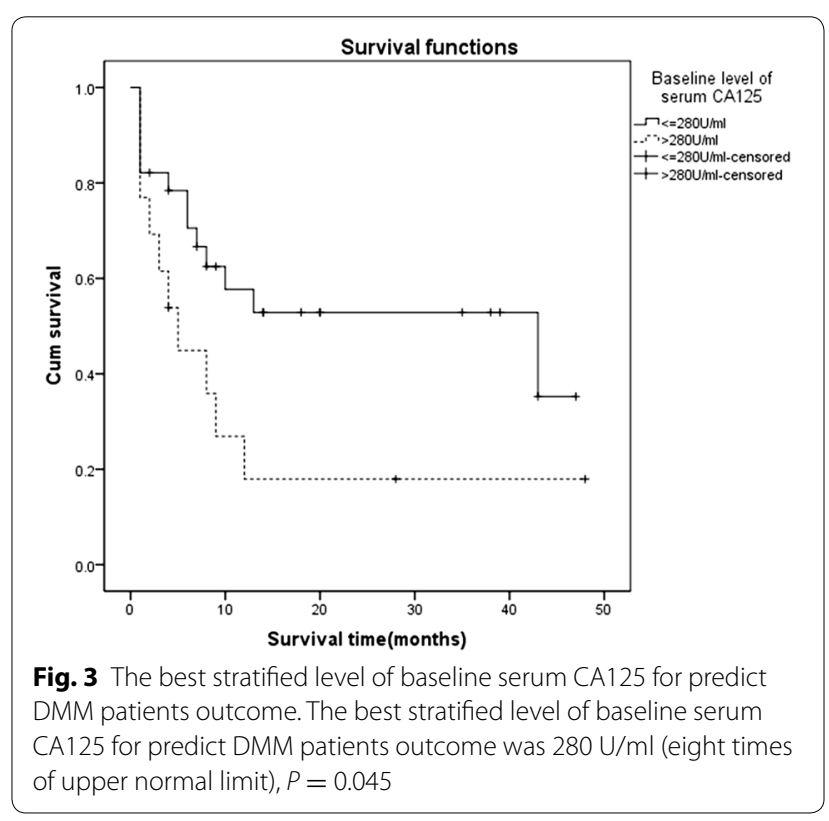

subgroup was $303.8 \mathrm{U} / \mathrm{ml}$ (range 10.19-1918 U/ml), while after receiving systemic chemotherapy, the mean level of serum CA125 was significantly declined to $96 \mathrm{U} /$ $\mathrm{ml}$ (range 5-462.9 U/ml). Figure 4 demonstrated the association between change in serum CA125 and OS. The change was divided into three grades: a decrease $>6 \mathrm{U} / \mathrm{ml}$, a change less than $6 \mathrm{U} / \mathrm{ml}$ (stable) and an increase $>6 \mathrm{U} / \mathrm{ml}$ (selected by Log-rank methods) and the decline in serum CA125 was associated with better OS in patients with systemic chemotherapy $(P=0.017)$.

\section{Discussion}

DMM is considered as a difficult disease condition to make a diagnosis and monitor disease progression 
Table 3 Prognostic significance of clinicopatholgic variables based on univariate analysis

\begin{tabular}{|c|c|c|c|c|c|c|c|c|}
\hline & \multirow[t]{2}{*}{ No. } & \multirow[t]{2}{*}{ Median OS (months) } & \multicolumn{4}{|c|}{ Survival at months (\%) } & \multirow[t]{2}{*}{ Hazard ratio } & \multirow[t]{2}{*}{ P value } \\
\hline & & & 6 & 12 & 18 & 24 & & \\
\hline \multicolumn{7}{|l|}{ Age } & 1.881 & 0.147 \\
\hline$\leq 60$ years & 28 & $13 \pm 10.2$ & 74.6 & 52.4 & 47.6 & 47.6 & & \\
\hline$>60$ years & 13 & $5 \pm 2.2$ & 34.6 & 26.0 & 26.0 & 26.0 & & \\
\hline \multicolumn{7}{|l|}{ Gender } & 1.850 & 0.157 \\
\hline Male & 28 & $43 \pm 25.1$ & 67.9 & 52.4 & 52.4 & 52.4 & & \\
\hline Female & 13 & $6 \pm 2.8$ & 45.1 & 22.6 & 11.3 & 11.3 & & \\
\hline \multicolumn{7}{|c|}{ Performance status (ECOG) } & 3.013 & 0.018 \\
\hline $0-1$ & 33 & $13 \pm 15.4$ & 68.3 & 53.0 & 48.9 & 48.9 & & \\
\hline 2 & 8 & $2 \pm 1.4$ & 37.5 & 12.5 & 12.5 & 12.5 & & \\
\hline \multicolumn{7}{|c|}{ Primary tumor location } & 0.236 & 0.003 \\
\hline Pleura & 23 & $6 \pm 2.1$ & 51.5 & 22.9 & 22.9 & 22.9 & & \\
\hline Pritoneum & 18 & - & 88.9 & 68.8 & 61.9 & 61.9 & & \\
\hline \multicolumn{7}{|c|}{ Histological subtype } & 2.281 & 0.006 \\
\hline Epithelial & 14 & $43 \pm 27.9$ & 85.7 & 85.7 & 85.7 & 85.7 & & \\
\hline Sarcomatoid & 1 & 13 & 1 & 1 & 0 & 0 & & \\
\hline Unspecified & 26 & $6 \pm 1.5$ & 56.7 & 20.4 & 20.4 & 20.4 & & \\
\hline \multicolumn{7}{|l|}{ Surgery } & 0.363 & 0.069 \\
\hline CRS & 11 & - & 90.0 & 70.0 & 60.0 & 60.0 & & \\
\hline $\mathrm{nCRS}$ & 30 & $7 \pm 2.0$ & 52.1 & 35.8 & 35.8 & 35.8 & & \\
\hline \multicolumn{7}{|c|}{ Systemic chemotherapy } & 0.340 & 0.015 \\
\hline Yes & 23 & $43 \pm 31.8$ & 77.1 & 60.9 & 55.4 & 55.4 & & \\
\hline No & 18 & $4 \pm 3.0$ & 43.8 & 25.0 & 25.0 & 25.0 & & \\
\hline \multicolumn{7}{|c|}{ Local chemotherapy } & 0.486 & 0.156 \\
\hline Yes & 13 & - & 61.5 & 61.5 & 61.5 & 61.5 & & \\
\hline No & 28 & $9 \pm 2.1$ & 61.6 & 37.3 & 32.0 & 32.0 & & \\
\hline \multicolumn{7}{|c|}{ Stage of disease } & 11.495 & 0.017 \\
\hline III & 10 & - & 88.9 & 88.9 & 88.9 & 88.9 & & \\
\hline IV & 31 & $7 \pm 2.5$ & 52.1 & 31.0 & 26.6 & 26.6 & & \\
\hline \multicolumn{7}{|c|}{ Baseline of CA125 } & 2.214 & 0.045 \\
\hline$\leq 280 \mathrm{U} / \mathrm{ml}$ & 28 & $43 \pm 23.4$ & 70.6 & 57.7 & 52.9 & 52.9 & & \\
\hline$>280 \mathrm{U} / \mathrm{ml}$ & 13 & $5 \pm 1.7$ & 44.9 & 17.9 & 17.9 & 17.9 & & \\
\hline
\end{tabular}

- , did not reach the median OS

because of its unspecific clinical signs and lack of effective tumor-related markers. Level of serum CA125 was elevated in DMM patients and it co-expressed with mesothelin which was regarded as an independent prognostic factor (Hollevoet et al. 2011; Linch et al. 2014). This retrospective study aimed to gain insight in the role of serum CA125 as biomarkers of response and outcome in patients with DMM.

In our study, we found the baseline level of serum CA125 might be considered as an independent prognostic factor for patients with DMM. The serum CA125 has been shown to distinguish malignant from benign, monitor therapeutic response and prognoses the OS for pelvic and ovarian cancer (Chen et al. 2013; Meyer and Rustin
2000). And its researches for malignant mesothelioma have been reported. Hedman et al. (2003) found that the level of serum CA125 increased as mesothelioma progressed in 5 patients, while 3 patients had a stable disease with a decrease in level of CA125. Kebapci et al. (2003) found the mean baseline serum CA125 level of 11 malignant peritoneal mesothelioma (MPeM) patients was $230 \mathrm{U} / \mathrm{ml}$. Baratti et al. $(2007,2009)$ reported that in nonpreoperative systemic chemotherapy subgroup, diffuse malignant peritoneal mesothelioma (DMPeM) patients with baseline CA125 $\leq 35 \mathrm{U} / \mathrm{ml}$ correlated to better OS compared with patients that baseline CA125 > $35 \mathrm{U} / \mathrm{ml}$ but failed to show the association between baseline levels of CA125 and OS in entire DMPeM patients. Our study 
Table 4 Prognostic significance of clinicopatholgic variables based on multivariate analysis

\begin{tabular}{|c|c|c|c|c|}
\hline \multirow[t]{2}{*}{ Parameters } & \multirow[t]{2}{*}{ Hazard ratio } & \multicolumn{2}{|c|}{$95 \% \mathrm{Cl}$} & \multirow[t]{2}{*}{$P$ value } \\
\hline & & Lower & Upper & \\
\hline Tumor location (pleura vs. peritoneum) & 0.289 & 0.096 & 0.870 & 0.027 \\
\hline Stage of disease (III vs. IV) & 14.571 & 1.825 & 116.326 & 0.011 \\
\hline Systemic chemotherapy (no vs. yes) & 0.298 & 0.099 & 0.900 & 0.032 \\
\hline Baseline level of serum CA125 ( $\leq 280$ vs. > $280 \mathrm{U} / \mathrm{ml}$ ) & 3.412 & 1.265 & 9.208 & 0.015 \\
\hline
\end{tabular}

Table 5 Correlation between the change in serum CA125 and the objective response

\begin{tabular}{lcrrl}
\hline No. & $\begin{array}{l}\text { Baseline } \\
\text { CA125 }\end{array}$ & $\begin{array}{l}\text { CA125 after } \\
\text { systemic CT }\end{array}$ & \multicolumn{1}{l}{$\begin{array}{l}\text { Change } \\
(\mathbf{U} / \mathbf{m l})\end{array}$} & Response \\
\hline 1 & 10.19 & 12.74 & 2.55 & SD \\
2 & 15.10 & 8.62 & -6.48 & SD \\
3 & 17.07 & 42.34 & 25.27 & PD \\
4 & 30.67 & 5.00 & -25.67 & PR \\
5 & 53.52 & 58.67 & 5.15 & PD \\
6 & 75.14 & 16.45 & -58.69 & SD \\
7 & 75.94 & 136.90 & 60.96 & SD \\
8 & 138.60 & 10.11 & -128.49 & SD \\
9 & 176.20 & 161.90 & -14.30 & SD \\
10 & 519.40 & 229.90 & -289.50 & SD \\
11 & 615.90 & 6.70 & -609.20 & PR \\
12 & 1918.00 & 462.90 & -1455.10 & PR \\
\hline
\end{tabular}

Systemic CT: systemic chemotherapy

The correlation coefficient rCA125 $=0.857 ; P<0.001$

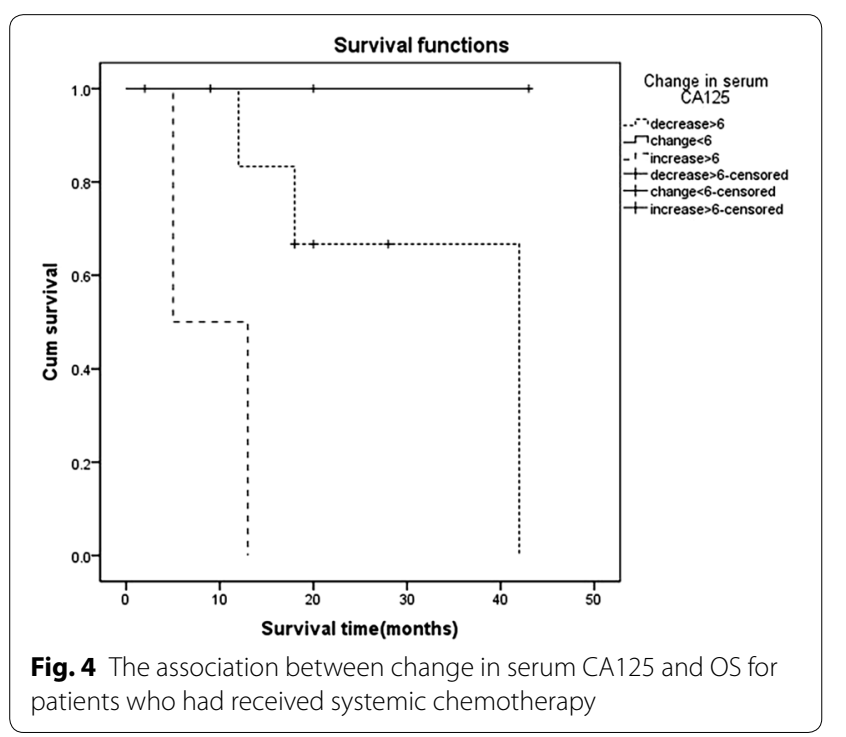

demonstrated patients with baseline CA125 > $280 \mathrm{U} / \mathrm{ml}$ (eight time of upper normal limit) had worse OS compared with the patients that baseline CA125 $\leq 280 \mathrm{U} / \mathrm{ml}$ in overall DMM patients.

Baseline level of serum CA125 $\leq 280 \mathrm{U} / \mathrm{ml}$ was also one of the independent prognostic factors for OS in multivariate analysis. Meanwhile, primary tumor location, stage of disease and systemic chemotherapy were the independent prognostic markers for DMM patients in our study and these factors have been confirmed in several papers (Vogelzang et al. 2003; Hollevoet et al. 2011; van der Bij et al. 2012; Tabata et al. 2013), supporting their close association with prognosis.

In systemic chemotherapy subgroup, the radiological responses according to modified RECIST criteria were significantly associated with relative changes in serum CA125 levels. The level of serum CA125 significantly decreased after receiving systemic chemotherapy and this tendency was accompanied with the disease control rate. Furthermore, our study demonstrated the change in serum CA125 could be a prognostic factor of OS for DMM patients who had received systemic chemotherapy. There are no previous reports focusing on this aspect.

The test of serum CA125 concentration is cheaper and more convenient adjunct to monitor patient response and prognosis than CT or MRI which are recommended for response evaluation and follow-up (Meyer and Rustin 2000; Stahel et al. 2009). Modified RECIST standard assessment is not adequate for DMM because DMM often present as a rind around the organs and pleural or peritoneal fluid rather than a spherical mass (van Klaveren et al. 2004), so we think serum CA125, like CT or MRI recommended by ESMO and NCCN guidance, should be included into regular tests to monitor the change of disease and predict the prognosis for DMM patients.

Our study had some limitations. It should be pointed out that our study was retrospective research with a small 
sample size. Some patients do not had specific pathological subtype may affect its role in prognosis. However, to our knowledge, our study is the first report to systematic analyzes the value of serum CA125 as a marker of response to therapy and prognosis in patients with DMM. Further validation of our findings is consequently required to elucidate the clinical value of CA125 in multicenter, larger samples prospective studies. We believe our results could provide some important information for clinical practice.

\section{Conclusions}

In conclusion, the current study identify the best stratified level of baseline serum CA125 associated with OS was $280 \mathrm{U} / \mathrm{ml}$. Baseline level of serum CA125, accompanied with stage of disease, primary tumor location and systemic chemotherapy, is an independent prognostic factor of DMM patients. For patients who receiving systemic chemotherapy, the change in serum CA125 could reflect the efficacy of systemic chemotherapy in keeping with modified RECIST criteria and predict OS.

\begin{abstract}
Abbreviations
MM: malignant mesothelioma; DMM: diffuse malignant mesothelioma; CRS: cytoreductive surgery; HIPEC: hyperthermic intraperitoneal chemotherapy; OS: overall survival; RECIST: Response Evaluation Criteria in Solid Tumors; MPeM: malignant peritoneal mesothelioma; PFS: progression-free survival; ECOG: Eastern Cooperative Oncology Group; DMPIM: diffuse malignant pleural mesothelioma; DMPeM: diffuse malignant peritoneal mesothelioma; ESMO: European Society for Medical Oncology; NCCN: National Comprehensive Cancer Network.
\end{abstract}

\section{Authors' contributions}

$\mathrm{XC}$ participated in the design of the study and drafted the manuscript. HG participated in the collection of data and performed the statistical analysis. $J L$ helped to draft the manuscript. DL helped to draft the manuscript. MQ conceived of the study, and participated in its design and coordination and helped to draft the manuscript. All authors read and approved the final manuscript.

\section{Author details}

1 Department of Medical Oncology, Cancer Center, West China Hospital, Sichuan University, No. 37, Guoxue Xiang Street, Chengdu 610041, Sichuan Province, China. ${ }^{2}$ West China School of Medicine, Sichuan University, Chengdu, Sichuan, China.

\section{Competing interests}

The authors declare that they have no competing interests.

Received: 7 January 2016 Accepted: 14 March 2016

Published online: 24 March 2016

\section{References}

Alexander HR Jr, Bartlett DL, Pingpank JF, Libutti SK, Royal R, Hughes MS, Holtzman M, Hanna N, Turner K, Beresneva T, Zhu Y (2013) Treatment factors associated with long-term survival after cytoreductive surgery and regional chemotherapy for patients with malignant peritoneal mesothelioma. Surgery 153(6):779-786
Baratti D, Kusamura S, Martinetti A, Seregni E, Oliva DG, Laterza B, Deraco M (2007) Circulating CA125 in patients with peritoneal mesothelioma treated with cytoreductive surgery and intraperitoneal hyperthermic perfusion. Ann Surg Oncol 14(2):500-508

Baratti D, Kusamura S, Deraco M (2009) Circulating CA125 and diffuse malignant peritoneal mesothelioma. Eur J Surg Oncol 35(11):1198-1199

Byrne MJ, Nowak AK (2004) Modified RECIST criteria for assessment of response in malignant pleural mesothelioma. Ann Oncol 15(2):257-260

Chen X, Zhang J, Cheng W, Chang DY, Huang J, Wang X, Jia L, Rosen DG, Zhang W, Yang D, Gershenson DM, Sood AK, Bast RC Jr, Liu J (2013) CA-125 level as a prognostic indicator in type I and type II epithelial ovarian cancer. Int J Gynecol Cancer 23(5):815-822

Creaney J, van Bruggen I, Hof M, Segal A, Musk AW, de Klerk N, Horick N, Skates SJ, Robinson BW (2007) Combined CA125 and mesothelin levels for the diagnosis of malignant mesothelioma. Chest 132(4):1239-1246

Creaney J, Dick IM, Dare H, Demelker Y, Nowak AK, Musk AW, Robinson BW (2013) Does CA125 binding to mesothelin impact the detection of malignant mesothelioma? Lung Cancer 80(1):39-44

de Pangher Manzini V, Brollo A, Franceschi S, de Matthaeis M, Talamini R, Bianchi C (1993) Prognostic factors of malignant mesothelioma of the pleura. Cancer 72(2):410-417

Edge SB, Byrd DR, Compton CC, Fritz AG, Greene FL, Trotti A (2010) AJCC cancer staging manual, vol 649. Springer, New York

Grigoriu BD, Scherpereel A, Devos P, Chahine B, Letourneux M, Lebailly P, Gregoire M, Porte H, Copin MC, Lassalle P (2007) Utility of osteopontin and serum mesothelin in malignant pleural mesothelioma diagnosis and prognosis assessment. Clin Cancer Res 13(10):2928-2935

Gubbels JA, Belisle J, Onda M, Rancourt C, Migneault M, Ho M, Bera TK, Connor J, Sathyanarayana BK, Lee B (2006) Mesothelin-MUC16 binding is a high affinity, $\mathrm{N}$-glycan dependent interaction that facilitates peritoneal metastasis of ovarian tumors. Mol Cancer 5(1):50

Hadi R, Saunders V, Utkina O, Clingan P, Kam P, Links M, Morris DL (2006) Review of patients with peritoneal malignancy treated with peritonectomy and heated intraperitoneal chemotherapy. ANZ J Surg 76(3):156-161

Hedman M, Arnberg H, Wernlund J, Riska H, Brodin O (2003) Tissue polypeptide antigen (TPA), hyaluronan and CA 125 as serum markers in malignant mesothelioma. Anticancer Res 23(1B):531-536

Herndon JE, Green MR, Chahinian AP, Corson JM, Suzuki Y, Vogelzang NJ (1998) Factors predictive of survival among 337 patients with mesothelioma treated between 1984 and 1994 by the Cancer and Leukemia Group B. Chest 113(3):723-731

Hollevoet K, Nackaerts K, Gosselin R, De Wever W, Bosquee L, De Vuyst P, Germonpre P, Kellen E, Legrand C, Kishi Y, Delanghe JR, van Meerbeeck JP (2011) Soluble mesothelin, megakaryocyte potentiating factor, and osteopontin as markers of patient response and outcome in mesothelioma. J Thorac Oncol 6(11):1930-1937

Kaneko O, Gong L, Zhang J, Hansen JK, Hassan R, Lee B, Ho M (2009) A binding domain on mesothelin for CA125/MUC16. J Biol Chem 284(6):3739-3749

Kao SC, Reid G, van Zandwijk N, Henderson DW, Klebe S (2011) Molecular biomarkers in malignant mesothelioma: state of the art. Pathology 43(3):201-212

Kebapci M, Vardareli E, Adapinar B, Acikalin M (2003) CT findings and serum ca 125 levels in malignant peritoneal mesothelioma: report of 11 new cases and review of the literature. Eur Radiol 13(12):2620-2626

Linch M, Gennatas S, Kazikin S, labal J, Gunapala R, Priest K, Severn J, Norton A, Ayite B, Bhosle J, O'Brien M, Popat S (2014) A serum mesothelin level is a prognostic indicator for patients with malignant mesothelioma in routine clinical practice. BMC Cancer 14:674

Meyer T, Rustin GJ (2000) Role of tumour markers in monitoring epithelial ovarian cancer. Br J Cancer 82(9):1535-1538

Mineo TC, Ambrogi V (2012) Malignant pleural mesothelioma: factors influencing the prognosis. Oncology (Williston Park) 26(12):1164-1175

Nonaka D, Kusamura S, Baratti D, Casali P, Cabras AD, Younan R, Rosai J, Deraco M (2005) Diffuse malignant mesothelioma of the peritoneum. Cancer 104(10):2181-2188 
Robinson BW, Lake RA (2005) Advances in malignant mesothelioma. N Engl J Med 353(15):1591-1603

Robinson BW, Creaney J, Lake R, Nowak A, Musk AW, de Klerk N, Winzell P, Hellstrom KE, Hellstrom I (2003) Mesothelin-family proteins and diagnosis of mesothelioma. Lancet 362(9396):1612-1616

Ruffie PA (1991) Pleural mesothelioma. Curr Opin Oncol 3(2):328-334

Rump A, Morikawa Y, Tanaka M, Minami S, Umesaki N, Takeuchi M, Miyajima A (2004) Binding of ovarian cancer antigen CA125/MUC16 to mesothelin mediates cell adhesion. J Biol Chem 279(10):9190-9198

Stahel R, Weder W, Felip E (2009) Malignant pleural mesothelioma: ESMO clinical recommendations for diagnosis, treatment and follow-up. Ann Oncol 20(Suppl 4):73-75

Tabata C, Shibata E, Tabata R, Kanemura S, Mikami K, Nogi Y, Masachika E, Nishizaki T, Nakano T (2013) Serum HMGB1 as a prognostic marker for malignant pleural mesothelioma. BMC Cancer 13:205

Troshichev O, Andrezen V, Vennerstrøm S, Friis-Christensen E (1988) Magnetic activity in the polar cap_a new index. Planet Space Sci 36(11):1095-1102 van der Bij S, Koffijberg H, Burgers JA, Baas P, van de Vijver MJ, de Mol BA, Moons KG (2012) Prognosis and prognostic factors of patients with mesothelioma: a population-based study. Br J Cancer 107(1):161-164 van Klaveren RJ, Aerts JG, de Bruin H, Giaccone G, Manegold C, van Meerbeeck JP (2004) Inadequacy of the RECIST criteria for response evaluation in patients with malignant pleural mesothelioma. Lung Cancer 43(1):63-69

Vogelzang NJ, Rusthoven JJ, Symanowski J, Denham C, Kaukel E, Ruffie P, Gatzemeier U, Boyer M, Emri S, Manegold C, Niyikiza C, Paoletti P (2003) Phase III study of pemetrexed in combination with cisplatin versus cisplatin alone in patients with malignant pleural mesothelioma. J Clin Oncol 21 (14):2636-2644

Zucali P, Ceresoli G, De Vincenzo F, Simonelli M, Lorenzi E, Gianoncelli L, Santoro A (2011) Advances in the biology of malignant pleural mesothelioma. Cancer Treat Rev 37(7):543-558

\section{Submit your manuscript to a SpringerOpen ${ }^{\odot}$ journal and benefit from:}

- Convenient online submission

- Rigorous peer review

- Immediate publication on acceptance

- Open access: articles freely available online

- High visibility within the field

- Retaining the copyright to your article

Submit your next manuscript at $\boldsymbol{~ s p r i n g e r o p e n . c o m ~}$ 